\title{
Alternativo
}

\section{AUTOCONHECIMENTO E AUTOESTIMA}

Elizete Ferreira Parnaíba Martins (1)

Maria de Lurdes Quaresma Dantas (2)

Francimeire Leite Pinheiro (3)

\section{Introdução}

O autoconhecimento sempre foi considerado uma busca permanente, pois trata-se de um assunto por demais subjetivo, que está relacionado a um objeto em constante mudança: o homem. Além disso, a introspecção como método empregado na sua descoberta envolve elementos da consciência, construto sujeito a percepções distorcidas, dada a interferências inconscientes.

Segundo Skinner (1993), o campo da consciência está no conhecimento de si. Assim, se o autoconhecimento está relacionado à consciência, é preciso verificar como esta consciência é abordada pelos diversos teóricos. Em primeiro lugar, "consciência" é uma metáfora (MATOS, 1995), os termos mais corretos seriam comportamentos conscientes. A palavra "consciência" remete à idéia de uma instância psíquica, um self decisor, enquanto "comportamento consciente".

Skinner (1982) nos orienta que a consciência é como um comportamento encoberto, que ocorre no universo que existe dentro da pele de cada um. Importante é esclarecer que eventos encobertos não apresentam natureza diferente dos eventos abertos, apenas são de mais difícil acesso, sem propriedades de originar comportamentos. Apesar de pertencer a escola behaviorista, Skinner diferencia-se dos behavioristas metodológicos, que não acreditavam na possibilidade de uma abordagem científica dos acontecimentos encobertos. Também se diferencia dos psicanalistas, que abordam a consciência como uma instância mental, com características próprias, e como causa de comportamentos.

Weber (2003) acredita numa consciência que corresponde a um comportamento verbal de autodescrição, isto é, uma capacidade de descrever ou relatar os próprios comportamentos. Skinner (1982) afirma que a pessoa está mais consciente quando está mais sensível ao controle do ambiente, ou seja, aumenta sua capacidade de discriminar e assim descrever seus comportamentos. Ter consciência de si corresponde ao comportamento de discriminar comportamentos próprios e variáveis que os controlam.

O autoconhecimento é autoconsciência, então, autoconhecimento é autodiscriminação de comportamentos e estímulos a eles relacionados. Autoconhecimento é um comportamento verbal discriminativo; expressa um conhecimento sobre o próprio comportamento (SKINNER, 1993). Neste caso, discriminação corresponderia a um processo de reforçamento diferencial, que torna uma dada resposta mais provável diante de um estímulo específico (CATANIA, 1999; SKINNER, 1993). Assim, o indivíduo emite comportamento verbal de descrição de seu próprio comportamento diante de estímulos discriminativos, por receber um reforço. Adianta-se aqui que este reforço é social, como será visto adiante. 
Na obra de Skinner, algumas vezes o autoconhecimento é tratado como discriminação de estados encobertos, e em outras, como discriminação de comportamentos do próprio indivíduo, incluindo todo e qualquer comportamento, mesmo o aberto (TOURINHO, 1993, citado em MARÇAL, 2003). Ressalta-se que, quando o indivíduo se auto-observa e autodescreve comportamentos encobertos, não está acessando comteúdos já existentes dentro de si num lugar imaterial.

Segundo Gongora e Abib (2001) O autoconhecimento não é um jeito ensinado para buscar algo no interior, também não é um caminho percorrido para atingir as profundezas do ser, é sim a descrição de comportamentos.

Se autoconhecer-se é um comportamento verbal descritivo, difere do comportamento descrito. Skinner (1982) diferencia o comportamento e o relato deste ou de suas causas: os comportamentos são produtos de contingências ambientais, mas a descrição de comportamentos abertos ou encobertos é produto de contingências específicas, verbais e organizadas por uma comunidade.

Vale abrir um parêntese aqui e lembrar que as contingências ambientais, relações de dependência entre dois eventos, controlam comportamentos independente-mente da "consciência" do indivíduo, por isso o comportamento operante é basicamente inconsciente (ROSE, 1982). "As relações controladoras entre o comportamento e as variáveis genéticas e ambientais são todas inconscientes, de vez que não são observadas..." (SKINNER, 1982, p. 133). Além de muitos de nossos próprios comportamentos não serem conscientes, as razões de sua ocorrência também não o são. Nem sempre as pessoas estão atentas às condições que antecedem seu comportamento, ou às conseqüências que ocorrem no ambiente, ou seja, não se discrimina a contingência. Assim, muitas vezes pergunta-se o porquê de uma atitude e o próprio indivíduo não consegue responder, acabase inventando razões para explicar o comportamento (SKINNER, 1982). A falta de consciência das ocorrências ambientais, relacionadas ao próprio comportamento, facilita a crença de que as causas são internas ao organismo.

Voltando à diferença entre o comportamento descrito e o descritivo, existe uma dificuldade em se reconhecer que, ao descrever um comportamento, dois comportamentos ocorrem - o comportamento descrito e o comportamento de descrever. Comer uma fruta como resposta ao estômago vazio é uma coisa e descrevê-lo é outra, porque se demonstra saber que se está com fome. Esses dois comportamentos estão sob controle de variáveis diferentes, um não dependendo necessariamente do outro (SÉRIO, 2001). As conseqüências do comportamento verbal descritivo são diferentes e especiais, por serem sempre mediadas por outras pessoas (SKINNER, 1978).

\section{O papel da sociedade no autoconhecimento}

Sendo autoconhecimento consciência de si, então significa conhecimento de si com os outros. "Auto" indica apenas o objeto do conhecimento, não que o conhecimento seja produzido por si mesmo (BATITUCCI, 2001).

Apesar do senso comum e do saber religioso transmitem a regra de que o isolamento é necessário para se atingir o autoconhecimento, Skinner (1993) defende que isso só pode ocorrer na interação social.

A origem da palavra consciência vem do latim comscience e significa co-conhecimento, ou seja, "conhecendo com outros" (SKINNER, 1990). Neste caso, o outro é necessário e imprescindível para o 
autoconhecimento. Isso só reafirma o caráter social do ser humano. "Não nos devemos surpreender com o fato de que quanto mais soubermos sobre o comportamento alheio, melhor nos compreendemos a nós mesmos" (SKINNER, 1982, p. 148). O comportamento dos outros diz muito sobre quem cada um é, pois muitas vezes é nele que se encontram as condições antecedentes ou as conseqüências dos comportamentos.

Como, então, a sociedade pode proporcionar o autoconhecimento? Reforçando diferencialmente o comportamento verbal de autodescrição. Assim, a sociedade é a responsável pelo processo de discriminação, que torna o comportamento de autodescrição contingente a um estímulo discriminativo e a um reforço social.

A sociedade não possui maneiras de acessar diretamente o mundo encoberto para ensinar as discriminações adequadas. Nas palavras de Skinner (1982, p.31):

“...nada é diferente enquanto não fizer diferença e, no que diz respeito aos acontecimentos do mundo dentro da pele, a comunidade verbal não foi capaz de tornar as coisas suficientemente diferentes" [...] "O autoconhecimento fica, assim, de certa forma, prejudicado, nunca será totalmente preciso. Esta limitação gera também outra consequiência, a desconfiança. Há tendência de suspeitar de dados acerca da estimulação encoberta, particularmente quando a descrição tem outras conseqüências".

A comunidade especializa-se em contingências autodescritivas, além de treinar a auto-observação instigando os membros a pensarem sobre si mesmos (SKINNER, 1983). "Tanto os repertórios verbais autodescritivos como a auto-observação, elementos indispensáveis para o auto-conhecimento, são instalados a partir de contingências providas pela sociedade" (MARÇAl, 2003).

A sociedade organiza as contingências para uma pessoa descrever o mundo aberto ou encoberto onde vive (mediante estímulos antecedentes - as perguntas, ou por meio de conseqüências) e então gera aquela forma muito especial de comportamento chamada "conhecimento" (SKINNER, 1982). Assim, a comunidade verbal ensina o indivíduo a se auto-observar e a descrever seus comportamentos, construindo o autoconhecimento. Como cada comunidade possui interesses diferentes, a maneira de uma pessoa se explicar aos outros e o tipo de autoconhecimento serão diferentes de uma comunidade para outra (SKINNER, 1982).

O autoconhecimento, segundo Skinner (1982) é inicialmente útil para a comunidade e, mais tarde, para o próprio indivíduo. Tal utilidade está relacionada à previsibilidade e à obtenção de reforços. A comunidade pode prever a obtenção de reforços com o autotato. Há maximização das possibilidades de reforços e isso mantém a construção do autoconhecimento (ROSE, 1982). Os comportamentos são reforçados pelo seu efeito nas outras pessoas, e, sabendo o que ela sente, pode-se aumentar a eficácia do efeito (SKINNER, 1982). Além disso, o próprio indivíduo é reforçado ao descrever seus comportamentos, quando consegue o que quer.

Ainda sobre o papel da sociedade para a construção do autoconhecimento, vale ressaltar que ela dispõe de um contexto especial em que o autoconhecimento se dá de forma mais sistemática e objetiva: o ambiente terapêutico. É certo que qualquer tipo de psicoterapia promove, de alguma forma, uma maior consciência de si no cliente. No entanto, a terapia comportamental se diferencia.

Tornar o cliente capaz de discriminar seus próprios comportamentos e as variáveis que o influenciam não é o objetivo da terapia, faz parte do processo, sendo necessário para capacitar o indivíduo a solucionar 
sozinho seus problemas (BATITUCCI, 2001). Com o auto-conhecimento, é possível partir para a construção de novos repertórios comportamentais.

$\mathrm{O}$ aparecimento da linguagem surgiu na história da espécie humana como um marco diferencial. Trouxe diversas vantagens, como maior possibilidade de cooperação, conselhos, instruções etc. (SKINNER, 1978), sendo a mais importante, aqui, o surgimento do autoconhecimento.

Com a linguagem, o ser humano passou a descrever seu próprio comportamento e tal descrição foi selecionada ao ser reforçada pela comunidade. Todo comportamento verbal é resultado de um processo de modelagem; os arranjos de contingências verbais numa comunidade são responsáveis pela construção do repertório verbal dos membros (GONGORA, 2003).

Dentre os tipos de comportamento verbal definidos por Skinner (1978), o tato é de especial interesse na presente discussão. O tato compreende um conjunto de verbalizações controlado por objetos e acontecimentos do meio físico. Corresponde a descrições de eventos físicos. Trata-se de um operante verbal que não especifica um reforçador, podendo ser considerado apenas informativo (BAUM, 1999). A criança aprende a dizer "isto é uma cadeira" diante da cadeira ou dizer "hoje o céu está azul" diante do céu azul, e é reforçada pela sociedade ao emitir estes comportamentos verbais. Assim, Segundo Gongora e Abib (2001), a sociedade ensina todo o repertório operante verbal discriminativo que é usado para descrever o mundo.

\section{O indivíduo e a liberdade a partir do conhecimento de si}

Quando o indivíduo se torna consciente de seus comportamentos, e talvez também dos fatores determinantes, surgem diversas vantagens, como o verdadeiro "ser livre", o autocontrole e a possibilidade de modificar o seu comportamento.

Ser livre é um sentimento que vem sendo defendido há tempos, com o erro de ser enfatizado como "estado de espírito associado ao fato de fazer o que se quer fazer" (SKINNER, 1993, p. 29). Um homem livre seria aquele que pode agir segundo sua vontade e pode realizar as escolhas de acordo com o que pensa. Esta realização das vontades, e propósitos, só é possível quando não há obstáculos. Assim, ser livre é estar longe de empecilhos que o impeçam de exercer a liberdade.

O ser humano vem lutando pela sua liberdade para evitar situações ou pessoas aversivas, ou seja, a sensação de ser livre está relacionada à fuga ou à esquiva de estímulos adversos (SKINNER, 1993). Ninguém faz o que quer, e sim, o que tem que fazer para evitar a punição ou escapar dela (SKINNER, 1982). Na verdade, são comporta-mentos selecionados pelo valor de sobrevivência, e a luta pela liberdade do ser humano tem sua funcionalidade. "É possível que a herança genética do homem favoreça esta espécie de luta pela liberdade" (SKINNER, 1993, p. 27).

Nota-se que há uma falsa noção de liberdade, pois, analisando segundo a ciência do comportamento, o "sentir-se livre" está sendo mantido por reforço negativo (ausência de consequiências punitivas), ou seja, o controle continua presente. Na verdade, todo comportamento humano é controlado por uma variável ambiental, mais especificamente pela história de reforçamento, não há alternativa. 
"A pessoa que afirma sua liberdade dizendo: "Eu resolvo o que farei a seguir" está falando de liberdade numa situação comum: $\mathrm{O}$ eu que assim parece ter uma opção é o produto de uma história da qual não está livre e que, de fato, determina o que ele fará agora". (SKINNER, 1982, p. 145)

Como as pessoas não percebem o controle? Não há nenhum antecedente imediato que possa servir como causa plausível para o comportamento operante sob reforço positivo, o que faz as pessoas atribuírem a causa à vontade, ao livre-arbítrio (Skinner, 1982). Assim, as pessoas "fazem o que querem", e, conseguindo o resultado, o re-forço positivo fortalece tanto o comportamento emitido quanto a regra de que é uma vontade interna que determinou o comportamento.

Além disso, o sentimento de liberdade é reforçado pela comunidade porque quando as pessoas estão sob efeito do reforço positivo não exercem contracontrole. "Sentir-se livre é um importante sinal distintivo de um tipo de controle que se singulariza pelo fato de não produzir contracontrole" (SKINNER, 1982, p. 169), sendo esse tipo de controle o reforço positivo. Skinner fornece o exemplo de um governo que, ao precisar levantar fundos, ao invés de obrigar as pessoas a pagarem taxas, organiza uma loteria; o controle existe nos dois casos, mas no segundo as pessoas "sentem-se livres" e não protestam.

Apesar de o ser humano ser reforçado a "sentir-se livre", ele não o é até o momento da tomada de consciência (SKINNER, 1993). O que Skinner quer dizer, é que a liberdade só existe quando o indivíduo discrimina seus comportamentos e as variáveis que os controlam, ou seja, a liberdade depende do autoconhecimento. Como já foi visto, o autoconhecimento só ocorre na relação com a comunidade, e assim é a interação do indivíduo com a comunidade que proporciona a liberdade. No entanto, o ser humano vem buscando o sentimento de liberdade em seu interior, e por isso Skinner (1982) afirma que o homem só vai conseguir sentirse verdadeiramente livre quando reconhecer o que é, o que sempre fracassou por ele buscar a solução no lugar errado.

"O extraordinário papel do meio ambiente abre a perspectiva de um futuro muito mais bem sucedido, no qual ele será muito mais humano e humanitário e no qual ele se conduzirá com maior habilidade porque se conhecerá mais acuradamente”. (SKINNER, 1982, p. 204)

Sendo a liberdade, segundo o ponto de vista skinneriano, possível a partir do autoconhecimento, ela sempre será limitada quanto aos eventos encobertos, tanto respostas quanto estímulos. A comunidade não é capaz de modelar a discriminação precisa de todos os comporta-mentos encobertos, e por isso o ser humano nunca se autoconhecerá totalmente e nem será livre totalmente. A liberdade total, como ausência de controles ou como autoconhecimento completo, não é possível. Segundo Skinner (1993, p.20):

"Esta possibilidade desagrada a muitas pessoas por se opor a uma tradição de longo tempo, que encara o homem como um agente livre, cujo comportamento é o produto, não de condições antecedentes específicas, mas de mudanças interiores espontâneas". 
A inexistência da liberdade como ausência de controle e movida por vontades e desejos internos é difícil de ser aceita. Skinner (1993) explica esta dificuldade de aceitação não pela vaidade humana ferida: Freud afirmou que o narcisismo humano teria sofrido três reveses, com as teorias de Copérnico, de Darwin e a sua. A quarta perda poderia ser com a teoria de Skinner, como relata Weber (2003), mas, em verdade, o que ocorre é o fato de a formulação científica destruir alguns reforçadores aos quais o ser humano estava acostumado. "A desagradável responsabilidade da ciência tem sido a de pintar um quadro mais realista" (SKINNER, 1993).

O maior conhecimento do real conceito de liberdade, dentro do behaviorismo radical, mostra que, em verdade, não há perdas e sim ganhos. A questão não está na possibilidade de sentir-se livre ou não. O importante não é "libertar os homens do controle, mas sim analisar e modificar as espécies de controle a que se acham submetidos" (SKINNER, 1993, p. 37). Esta visão é muito mais otimista, pois permite manipulação de variáveis com o objetivo de mudança tendo por base o autoconhecimento e a liberdade. A nova forma de Skinner ver o homem não como um ser predeterminado, e sim em constante aperfeiçoamento e de forma ativa, não passiva (BATITUCCI, 2001), permite muito mais o exercício da liberdade do que em outros pressupostos teóricometodológicos em que se seguem determinações anteriores e definitivas.

Já se dizia na literatura da liberdade, antes do behaviorismo radical, da importância de tornar as pessoas conscientes das situações adversas em que viviam, mas não se ofereciam alternativas para sair dessas situações (SKINNER, 1993). Skinner cita um exemplo sobre "melhor ser escravo consciente do que escravo feliz", mas melhor ainda seria deixar de ser escravo, e é isso que o behaviorismo radical possibilita. Aí está a verdadeira liberdade, saber qual é o problema, poder manipular as variáveis e modificar seu comportamento e, conseqüentemente, a situação.

Tratar a liberdade como um sentimento que possibilita fazer as vontades pessoais é um erro, porque este ponto de vista impede de se lidar efetivamente com técnicas de controle (SKINNER, 1993). A utilidade do autoconhecimento e, portanto, da liberdade, está justa-mente na previsão e no controle do comportamento (SKINNER, 1982). A própria pessoa pode prever seu comportamento e fazer algo para fortalecê-lo ou evitá-lo, como ocorre no caso do autocontrole.

Skinner (1993) descreve diversas técnicas de autocontrole, como a restrição física, a mudança de estímulos, privação e saciação, uso de estimulação aversiva e assim por diante. Uma pessoa é capaz de controlar estímulos para modificar seu próprio comportamento. O autoconhecimento se comporta como ferramenta auxiliar para mudança de comportamento por meio do autocontrole, sendo uma condição necessária, mas não suficiente, para a aquisição de autocontrole (BECKERT e RODRIGUES, 2002). Ressalta-se que a probabilidade de modificação do meio é maior quando o autoconhecimento é mais elaborado, não sendo apenas a discriminação dos próprios comportamentos, mas também a discriminação das condições nas quais faz o que faz (BATITUCCI, 2001).

No autocontrole pode-se dizer que o comportamento é proposital. O propósito não é causa, é apenas o indício de que uma pessoa age com consciência das conseqüências reforçadoras. As razões são, segundo Skinner (1982), as consequiências reforçadoras que mantêm o comportamento; quando o indivíduo tem consciência dessas razões, pode-se dizer que o comportamento é proposital (ROSE, 1982). Com isso, percebe-se como o autoconhecimento possibilita comportamentos propositais e, assim, maximização de reforçamento positivo para o indivíduo. 
O controle por reforçamento positivo é o único tipo de controle não coercitivo (SIDMAN, 2001). A coerção, que envolve reforçamento negativo e punição, está muito presente na vida do ser humano sem que ele a perceba. Skinner demonstra isso ao descrever o controle exercido pelas agências controladoras (governo, escola, família, religião). Certamente, o controle coercitivo também promove autoconhecimento, mas tem seu lado negativo pelos produtos colaterais que o acompanham, como comporta-mentos de fuga e esquiva que prejudicam o desenvolvimento de repertórios no indivíduo (SIDMAN, 2001).

Com o autoconhecimento, o ser humano pode planejar sua vida. Não pode ser totalmente livre, mas pode manipular o ambiente, trocando controles coercitivos por menos coercitivos (CARVALHO NETO, 2000). Esta mudança contribuiria para um relacionamento interpessoal mais positivo.

\section{Auto-estima e autovalorização}

Entende-se por auto-estima um conjunto de sentimentos e pensamentos do indivíduo sobre seu próprio valor, competência e adequação, que se reflete em uma atitude positiva ou negativa em relação a si mesmo (ROSENBERG, 1965). Coopersmith (1989) ressalta que o ponto fundamental da auto-estima é o aspecto valorativo, o que influencia na forma como o indivíduo elege suas metas, aceita a si mesmo, valoriza o outro e projeta suas expectativas para o futuro (BEDNAR e PETERSON, 1995).

Pode ser avaliada segundo níveis: baixo, médio e alto. A baixa auto-estima caractariza-se pelo sentimento de incompetência, de inadequação à vida e incapacidade de superação de desafios; a alta expressa um sentimento de confiança e competência; e a média flutua entre o sentimento de adequação ou inadequação, manifestando essa inconsistência no comportamento (BRANDEN, 2000; ROSENBERG, 1956/1989).

Estudos que avaliam a importância da auto-estima proliferam nos países desenvolvidos, destacando-se dentre os indicadores de saúde mental e nas análises sociais de crescimento e progresso (MRUK, 1995).

A auto-estima relaciona-se a construtos psicológicos como bem-estar (SÁNCHEZ e BARRÓN, 2003) e autoconceito (MARTÍN-ALBO, NÚÑEZ, NAVARRO e GRIJALVO, 2007), sendo amplamente investigada no campo da psicologia da personalidade (SCHMITT e ALLIK, 2005). Alguns pesquisadores têm visto a autoestima como traço (refletindo estabilidade durante um período de tempo) e estado (refletindo uma resposta a situações ou eventos de vida) (HARTER e WHITESELL, 2003); enquanto outros sugerem que o desenvolvimento deste atributo possui descontinuidades ao invés de um curso estável ao longo do ciclo vital (Cole e cols., 2001).

A auto-estima é considerada um dos principais preditores de resultados favoráveis na adolescência e na vida adulta, tendo implicações em áreas como sucesso ocupacional, relacionamentos interpessoais e desempenho acadêmico (TRZESNIEWSKI, DONNELLAN e ROBINS, 2003). Por outro lado, a influência desta característica também tem sido observada em problemas adversos como agressão, comportamento antissocial e delinquência na juventude (DONNELLAN, TRZESNIEWSKI, ROBINS, MOFFITT e CASPI, 2005).

Dada a sua relação com o ajustamento psicossocial, a auto-estima tem sido vista como um importante indicador de saúde mental e um fator relevante nas análises de crescimento e progresso nos países desenvolvidos (MRUK, 1995). Adicionalmente, a avaliação desta característica vem sendo considerada uma ferramenta importante na identificação e na prevenção de problemas psicológicos (FAN e FU, 2001). 
A mensuração da auto-estima tem sido mundialmente realizada por meio da Escala de Auto-estima de Rosenberg - EAR (ROSENBERG, 1965), conceitualizada pelo autor como um instrumento unidimensional capaz de classificar o nível de auto-estima em baixo, médio e alto. A baixa auto-estima se expressa pelo sentimento de incompetência, inadequação e incapacidade de enfrentar os desafios; a média é caracterizada pela oscilação do indivíduo entre o sentimento de aprovação e rejeição de si; e a alta consiste no autojulgamento de valor, confiança e competência (ROSENBERG, 1965). A escala original foi desenvolvida para adolescentes e possui dez sentenças fechadas, sendo cinco referentes à "auto-imagem" ou "autovalor" positivos e cinco referentes à "auto-imagem negativa" ou "autodepreciação". As sentenças são dispostas no formato Likert de quatro pontos, variando entre "concordo totalmente" e "discordo totalmente".

A EAR foi traduzida para 28 idiomas e sua difusão em até 53 países tem revelado problemas referentes à estrutura unidimensional (SCHMITT e ALLIK, 2005). Vários pesquisadores realizaram a análise fatorial dos itens da escala e encontraram um construto bidimensional, que se reflete nas imagens positiva e negativa que o indivíduo possui de si mesmo (AVANCI, ASSIS, SANTOS e OLIVEIRA, 2007; HATCHER e HALL, 2009; ROJAS-BARAHONA, ZEGERS e FÖRSTER, 2009). Contudo, também há evidências confirmando o modelo de um fator para a EAR, o que torna sua estrutura fatorial uma questão controversa (ALUJA, ROLLAND, GARCÍA e ROSSIER, 2007; MARTÍN-ALBO e cols., 2007; SCHMITT e ALLIK, 2005; SINCLAIR e cols., 2010).

Do ponto de vista teórico, a dimensionalidade da autoestima também vem sendo questionada. Autores como Harter (1999) e Coopersmith (1989), que há décadas têm estudado este conceito, sustentam o seu caráter multidimensional. Isso porque, além de uma possível decomposição do construto em fatores, os autores consideram importante avaliar esta característica em diferentes domínios (social, escolar, familiar, etc.), já que os sujeitos podem ter percepções positivas de si em algumas áreas e não em outras.

Ainda que existam controvérsias sobre o conceito de auto-estima e sua estrutura fatorial, a EAR tem apresentado bons índices de consistência interna em pesquisas internacionais, que foram realizadas com amostras de adolescentes e adultos (ALUJA e cols., 2007; DONNELLAN e cols., 2005). A adolescência tem sido a faixa etária mais pesquisada, sendo esta marcada por intensas mudanças físicas, sociais e cognitivas, que estão ligadas à construção e manutenção dessa característica psicológica (ROBINS, HENDIN e TRZESNIEWSKI, 2001).

Harter (1999) destaca que, na adolescência, a noção do autovalor torna-se um aspecto central porque os indivíduos desenvolvem capacidades cognitivas que lhes permitem realizar abstrações a respeito do self. Nesse período, o jovem também passa a atribuir maior importância à percepção que os outros têm sobre ele, o que parece levar, segundo pesquisas, a uma redução nos níveis de auto-estima na adolescência inicial e média (CLAY, VIGNOLES e DITTMAR, 2005; HEAVEN e CIARROCHI, 2008). Contudo, os achados são inconclusivos, pois um estudo longitudinal, por exemplo, indicou que jovens americanos tiveram um aumento de auto-estima na adolescência inicial, seguido de decréscimo na adolescência média, havendo novamente um aumento no final da adolescência (BALDWIN e HOFFMANN, 2002).

Quanto ao gênero, Harter (1999) explica que as meninas apresentam mais conflitos durante o desenvolvimento da auto-imagem, pois valorizam mais os relacionamentos interpessoais e a opinião das outras pessoas a seu respeito, o que pode levá-las a índices mais baixos de auto-estima. No entanto, não há consenso nas pesquisas quanto à existência de diferença neste atributo em adolescentes do sexo masculino e feminino. 
Pesquisas realizadas com adolescentes na Austrália e no Reino Unido indicaram um maior decréscimo de autoestima nas jovens (HEAVEN e CIARROCHI, 2008; ROBINS e TRZESNIEWSKI, 2005). Estudos realizados na Espanha e Europa mostraram que a noção de autovalor dos meninos foi apenas um pouco mais elevada que a das meninas (MARTIN-ALBO e cols., 2007; VELESKA e cols., 2009). Por outro lado, dois estudos de metanálise não revelaram diferenças de gênero para autoestima na adolescência (GENTILE e cols., 2009; TWENGE e CAMPBELL, 2001).

$\mathrm{Na}$ literatura nacional, entretanto, o construto auto-estima tem sido pouco investigado, especialmente em estudos realizados com amostras com grande número de participantes, o que dificulta o conhecimento deste aspecto em nossa população (AVANCI e cols., 2007; BANDEIRA, ARTECHE e REPPOLD, 2008). Dentre as pesquisas nacionais encontradas, algumas apontam relações entre auto-estima e gênero na adolescência, indicando escores ligeiramente superiores em jovens do sexo masculino (ROMANO, NEGREIROS e MARTINS, 2007; SANTOS e MAIA, 2003). Com relação à estrutura fatorial da EAR, os estudos realizados no Brasil têm refletido as divergências encontradas na literatura, já que existem evidências corroborando tanto a unidimensionalidade da escala (HUTZ, 2000; SANTOS e MAIA, 2003), quanto a existência de uma estrutura bifatorial (ANDRADE, SOUSA e MINAYO, 2009; AVANCI e cols., 2007; ROMANO e cols., 2007).

Em resumo, este capítulo pôde esclarecer os conceitos de autoconhecimento e de auto-estima. São termos importantes de serem discutidos, pois são muitas vezes mal interpretados. Pôde-se refletir aspectos relacionados ao behaviorismo que estuda os eventos internos, possibilitadores da liberdade do indivíduo.

Percebeu-se que para Skinner (1982). O autoconhecimento é definido como comportamento verbal descritivo que permite a liberdade. Esta é a relação entre os dois conceitos, para o indivíduo controlar seu próprio comportamento precisa necessariamente se autoconhecer. $\mathrm{O}$ autoconhecimento também pode possibilitar uma maior auto-estima, na medida em que torna mais preciso o conhecimento de si.

Mais especificamente diversos são os problemas detectados entre os estudantes, tais como: a violência familiar, o abuso de drogas, a gravidez precoce, o fraco desempenho escolar, a delinquência, o suicídio, as agressões escolares, a depressão e a prostituição, em muitos casos associados a baixa auto-estima (ASSIS e AVANCI, 2003; DOURADO, 1984, GOMES, 1994; ROSENBERG, 1956; TAMAYO e CUNHA, 1983).

Embora a importância da auto-estima, para o bem-estar social e individual seja reconhecida internacionalmente, no Brasil, há escassez de estudos sobre a temática, especificamente em bases populacionais.

Os conceitos de autoconhecimento, auto-estima e liberdade são ferramentas que podem ser utilizadas na melhoria da qualidade de vida do ser humano, e os psicólogos e pedagogos podem fazer uso delas. Seja qual for a área de atuação, o profissional está sempre trabalhando com outros indivíduos. No caso mais específico dos educadores, é imprescindível o autoconhecimento para que possa agir da melhor forma com os outros, sempre atento para ser o menos coercitivo possível. Este comportamento, certamente criará melhores condições para proporcionar autoconhecimento aos seus alunos e pares e, em muitos casos melhorar a auto-estima dos alunos sob sua responsabilidade.

\section{Referências}

ASSIS, S.G. e AVANCI, J.Q. Labirinto de espelhos. A formação da auto-estima na infância e adolescência. Rio de Janeiro, RJ: Editora Fiocruz, 2003. 
BATITUCCI, L. A. V. Autoconhecimento em contexto clínico uma abordagem behaviorista radical. Monografia apresentada à Faculdade de Ciências da Saúde, do Centro Universitário de Brasília - UNICEUB. 2001. Disponível em: 〈http://www.ibac.com.br/doc/downloads/ monografia_luiz_anisio.pdf>. Acesso em: 4/12/03.

BAUM, W. M. Compreender o behaviorismo: ciência, comportamento e cultura. Porto Alegre: Artes Médicas Sul, 1999.

BECKERT, M. E. \& RODRIGUES, J. A. autoconhecimento, autocontrole e terapia analítico-comporta-mental. Anais XI Encontro Nacional da Associação Brasileira de Psicoterapia e Medicina Comportamental, Campinas, 112, 2002.

BRANDEN, N. Auto-estima: como aprender a gostar de si mesmo. São Paulo, SP: Saraiva, 2000.

CARVALHO NETO, M. B. Esclarecimentos sobre o behaviorismo: uma réplica a Japyassú. Revista de Etologia, 2000. 2(1), 43-55.

CATANIA, A. C. Aprendizagem: comportamento, linguagem e cognição. Porto Alegre: Artes Médicas Sul, 1999.

GONGORA, M. A. N. Itinerário para analisar comportamento verbal encoberto. Em M. Z. Brandão (Org.). Comportamento e cognição (vol. 11, pp. 66-81). Santo André, SP: ESETec Editores Associados, 2003.

GONGORA, M. A. N. e ABIB, J. A. D. Questões referentes à causalidade e eventos encobertos no behaviorismo radical. Revista Brasileira de Terapia Comportamental e Cognitiva, 2001. 3(1), 4-29.

COOPERSMITH, S. The Antecedents of self-esteem. San Francisco: Freeman, 1967.

DOURADO, J.M.B. O rendimento acadêmico e sua relação com o auto-conceito do aluno e a retoralimentação do professor. Dissertação de mestrado não-publicada. Universidade de Brasília. DF, 1984.

GIACOMMI, C.H. ( Bem-estar subjetivo infantil: conceito de felicidade e construção de instrumentos para avaliação. Tese de doutorado não-publicada, curso de Pós-graduação em psicologia do desenvolvimento, Universidade Federal do Rio Grande do Sul, Porto Alegre-RS, 2002.

GOMES, R.A. Violência enquanto agravo á saúde das meninas que vivem nas ruas. Cadernos de saúde Pública, 1994. 10 (1), 156-167.

HUTZ, C.S. Adaptação brasileira da escala de auto-estima de Rosenberg. Curso de Pós-graduação em psicologia do Desenvolvimento, Universidade Federal do Rio Grande do Sul, RS, 2000.

MARÇAL, J. V. S. O autoconhecimento no behaviorismo radical de Skinner, na filosofia de Gilbert Ryle e suas diferenças com a filosofia tradicional apoiada no senso comum. 2003. Disponível em: <http://www.ibac.com.br/doc/downloads/ artigo__arcal_autoconhecimento_skinner.pdf>. Acesso em: 4/12/03.

MATOS, M. A. Behaviorismo metodológico e behaviorismo radical. Em B. Range (Org.). Psicoterapia comportamental e cognitiva: pesquisa, prática, aplicações e problemas , 1995, (pp. 27-34). Campinas: Psy.

MECCA, A. SMELSER, N.J E VASCONCELOS, J. The social importance of self-esteem. Berkeley, CA: University of California Press, 1989.

MRUK, C. Self-esteem: Reserch, Theory, and pratice. New York: Springer, 1995.

ROSE, J. C. Consciência e propósito no behaviorismo radical. Em B. Prado Júnior (Org.). Filosofia e comportamento. São Paulo: Brasiliense. 1982. Dispo-nível em: <http://www.cemp.com.br/textos7.htm>. Acesso em: 4/12/2003. 
ROSENBERG, M. Society and adolescent self-image. Princeton, NJ: Princeton University Press. (Original publicado em 1956), 1989.

SÉRIO, T. M. A. P. A concepção de homem e a busca de autoconhecimento: onde está o problema. Em R. A.

Banaco (Org.). Comportamento e cognição (vol. 1, pp. 206-212). Santo André, SP: ESETec Editores Associados, 2001.

SIDMAN, M. Coerção e suas implicações. Campinas: Livro Pleno, 2001.

SKINNER, B. F. O mito da liberdade. São Paulo: Summus, 1972.

SKINNER, B. F. O comportamento verbal. São Paulo: Cultrix, 1978.

SKINNER, B. F. Sobre o behaviorismo. São Paulo: Cultrix, 1982.

SKINNER, B. F. Can psychology be a science of mind? American Psychologist,1990, 45(11), 1206-1210.

SKINNER, B. F. Ciência e comportamento humano. São Paulo: Martins Fontes, 1993.

Souza, D.B.L. DE, e FERREIRA, M.C. Auto-estima pessoal e coletiva em mães e nãao-mães. Psicologia em estudo, 2005. 10(1), 19-25.

TAMAYO, A. e CUNHA, P. Autoconceito, sexo e frequência de atividade sexual Pré-marital. Ciência e Cultura, 1983. 35 (7).

WEBER, L. N. D. Conceitos e pré-conceitos sobre o behaviorismo. Revista Psicologia Argumento, 2002. 20(31), 29-38.

WEBER, L. N. D. Skinner: um homem além de seu tempo. Em P. I. C. Gomide \& L. N. D. Weber. Análise experimental do comportamento: manual de laboratório. 6a ed. (pp. 129-149). Curitiba: Ed. da UFPR, 2003.

\section{Sobre as Autoras:}

(1) Elizete Ferreira Parnaíba Martins é Graduada em Pedagogia pela Universidade Federal de Campina Grande e Pós-graduada em Metodologia do Ensino Fundamental pela Faculdade São Francisco Cajazeiras/PBD. Especialista em Docência do Ensino Superior pela Faculdade Kurius e Mestranda em Ciências da Educação pela Universidade San Carlos - Ciudad Del Este.

E-mail: elizeteferreirasth@hotmail.com

(2) Maria de Lurdes Quaresma Dantas é Graduada em Pedagogia pela Universidade Vale do Acaraú UVA e Especialista em Docência do Ensino Superior pela Faculdade Kurius. Mestranda em Ciências da Educação pela Universidade San Carlos - Ciudad Del Este.

(3) Francimeire Leite Pinheiro, é Especialista em Docência do Ensino Superior pela Faculdade Kurius. Mestranda em Ciências da Educação pela Universidade San Carlos - Ciudad Del Este.

E-mail: merinhaleitepinheiro@hotmail.com.

\section{Como citar este artigo (Formato ISO):}

MARTINS, E.F.P.; DANTAS, M.L.Q.; PINHEIRO, F.L. Autoconhecimento e Auto-estima. Id on Line Revista de Psicologia, Novembro de 2011, vol.1, no.15, p.37-47. ISSN 1981-1189. 